\title{
A inserção de um agente conversacional animado em um ambiente virtual de aprendiza- gem a partir da teoria da carga cognitiva
}

Leila Maria Araújo Santos

Orientadora: Profa. Dra. Liane MargaridaRockenbachTarouco

Coorientador: Prof. Dr. Eliseo Berni Reategui

Data da defesa: 16 de outubro de 2009.

Este trabalho relata um experimento realizado durante um curso totalmente a distância, oferecido aos alunos da UAB/UFSM em parceria com a Coordenadoria de Educação a Distancia da UFSM. Este curso teve a participação de 312 alunos divididos em duas turmas. A turma A teve a inserção de um agente conversacional no ambiente virtual de aprendizagem utilizado no curso. A turma $B$ recebeu o mesmo conteúdo da turma $A$, mas não contou com a presença do agente conversacional. Este estudo teve por objetivo verificar de que maneira a inserção de um agente conversacional em um ambiente virtual de aprendizagem interfere na carga cognitiva dos materiais educacionais e influencia o desempenho e engajamento dos estudantes, no contexto do ensino a distância. Diferentemente de outros estudos realizados sobre este assunto, este trabalho tem como foco o estudo da Carga Cognitiva, pois estudos mostram da importância da Carga Cognitiva no desempenho de alunos que interagem com a tecnologia, seja no ensino presencial ou a distância (SWELLER, 2000). Para a realização deste estudo buscou-se na Teoria da Carga Cognitiva fundamentação teórica para este estudo. Este trabalho relata contribuições importantes para o uso de agentes na EAD, pois verificou-se que os agentes conversacionais podem contribuir para o processo de aprendizagem, provavelmente, como demonstrado neste estudo, não diretamente no grau de desempenho do aluno, mas podem enriquecer a experiência de aprendizagem, oferecendo ambientes mais dinâmicos, favorecendo o conteúdo apresentado através de interações mais amigáveis ou colaborando para a diminuição da carga cognitiva global do material educacional.

Palavras-chave: Teoria da Carga Cognitiva. Ambientes virtuais de aprendizagem, Agentes conversacionais.

Referência:

SANTOS, Leila Maria Araújo. A inserção de um agente conversacional em um ambiente virtual de aprendizagem a partir da Teoria da Carga Cognitiva - Orientadora: Liane Margarida Rockenbach Tarouco. Coorientador: Eliseo Berni Reategui - 2009. Tese (doutorado) - Programa de Pós-Graduação em Informática na Educação, Centro de Estudos Interdisciplinares em Novas Tecnologias da Educação, Universidade Federal do Rio Grande do Sul, 2009, Porto Alegre. 